\title{
VOM VERLUST DER ERSTEN EINSICHTEN. DIE SCHULDFRAGE IN DER DEUTSCHEN LITERATUR UNMITTELBAR NACH KRIEGSENDE UND IHRE BEDEUTUNG FÜR DIE AUFARBEITUNG DER NS-GESCHICHTE IN DEUTSCHLAND
}

\author{
BERND F. W. SPRINGER \\ Universitat Autònoma de Barcelona \\ bernd.springer@uab.cat
}

\section{ZUSAMMENFASSUNG}

Der Artikel bietet zunächst einen interpretativen Überblick über die wesentlichen Phasen der deutschen Aufarbeitung des 3. Reiches, bis hin zu jenem Erinnerungsboom in Literatur und Film, der Ende der Neunziger Jahre einsetzte. Dieser Boom ist einerseits gekennzeichnet durch eine extreme Kommerzialisierung der Vergangenheit, andererseits aber auch durch kritische Rückblicke auf frühere Phasen des Erinnerns, in denen eine klare Instrumentalisierung des Schuldvorwurfs der Nachkriegsgeborenen gegen ihre Elterngeneration aufgedeckt wird. Die Erkenntnis leitende Motivation nachgeborener Generationen hatte teilweise, so der Vorwurf, mehr mit eigenen moralischen und politischen Projektionen als mit der Vergangenheit und ihren Akteuren selber zu tun. Das legt die Hypothese nahe, dass die literarische Suche nach Wahrheit und Gerechtigkeit mit zunehmender zeitlicher Distanz zum 2. Weltkrieg an Glaubwürdigkeit verlor. Dafür würde sprechen, und das macht den zweiten Teil der Untersuchung aus, dass viele unmittelbar nach Kriegsende publizierten und teilweise noch im Krieg verfassten Texte auf eine viel differenziertere Weise die sehr unterschiedlichen Grade der Verstrickung in das Böse offenlegten, als dies in späteren Jahrzehnten üblich war. Sie kannten vielfältige Möglichkeiten des Schuldig-Werdens und präsentierten sogar Situationen, in denen es unmöglich ist, nicht schuldig zu werden. Diese Einsichten in das moralische Dilemma der menschlichen Existenz, so die These des Artikels, gingen in den folgenden Jahrzehnten weitgehend verloren.

SCHLÜSSELWÖRTER: NS-Geschichte, Vergangenheitsaufarbeitung, Schuldfrage,

Erinnerungsboom.

\section{ABOUT THE LOSS OF THE FIRST INSIGHTS. THE QUESTION OF GUILT IN THE GERMAN LITERATURE IMMEDIATELY AFTER THE SECOND WORLD WAR AND ITS IMPORTANCE FOR THE HISTORICAL REAPPRAISAL OF THE THIRD REICH IN GERMANY.}

ABSTRACT

The article offers first an interpretative overview about the essential phases of German historical reappraisal of the Third Reich up to that memory boom in literature and film, which started in the end of the nineties. This boom is marked, on the one hand, by an extreme commercialisation of the past, on the other hand, however, also by critical reviews on former phases of historical memory, in which is disclosed a misuse for other purposes of the reproach 
of being guilty, made by parts of the post-war-born against their parental generation. The epistemic interest and motivation of post-war-generations partially dealt, according to the critical reviews, more with own moral and political projections than with the past and its actors itself. This suggests the hypothesis that, with an increasing temporal distance to the Second World War, the literary search for truth and justice lost credibility. An argument for this would be, and this puts out the second part of the article, that many literary and philosophical attempts of understanding the horror, written during and/or published immediately after the end of the war, uncovered in a much more differentiated way the various degrees of the entanglement into the Evil. They knew a great variety of becoming guilty and presented even situations, in which it is impossible not to become guilty. These insights of the moral dilemma of human condition, according to the thesis of the article, got lost to a large extend in the following decades.

KEYWORDS: History of National Socialism, historical reappraisal, question of guilt, memory boom.

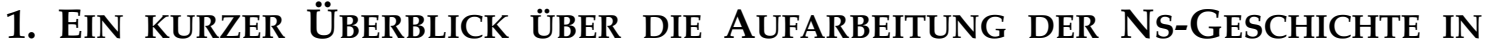 DEUTSCHLAND}

In den 50er Jahren herrschte in Westdeutschland eine weit verbreitete Stimmung, die sich in dem damals oft geäußerten Satz spiegelte: „Wenn der Hitler das mit den Juden nicht gemacht hätte!“ Insgesamt waren viele Bundesbürger vom Nazi-Regime vor allem deshalb enttäuscht, weil es Deutschland in eine katastrophale Niederlage geführt hatte und weil man sich zusätzlich vor aller Welt wegen des Völkermords schämen musste. Die Einsicht in das Leid, das das NS-Regime über andere Völker gebracht hatte, hielt sich dagegen in Grenzen, denn die meisten Deutschen fühlten sich selber als Opfer: als Opfer des Bombenkriegs und als Opfer von Flucht und Vertreibung im Osten. Schon bald

entwickelte sich ein immer deutlicherer Gegensatz zwischen Westdeutschland, das die Niederlage und moralische Demütigung nicht annehmen konnte, und Ostdeutschland, das (jedenfalls nach eigener Lesart) die Geschichte voll akzeptiert hatte und sich als Teil des antifaschistischen Widerstandes betrachtete und nicht als besiegtes faschistisches Land. (Judt, Snyder 2015: 55). ${ }^{1}$

Die Sowjetunion hatte den Krieg gegen Deutschland nämlich als antifaschistischen Krieg dargestellt, nicht als antideutsches Unternehmen und auch nicht als Befreiung von rassistischer Besatzung. Mit dem Ergebnis, dass die Befreiung der Konzentrationslager und das Leid ihrer Insassen in der sowjetischen Geschichtsschreibung keine herausgehobene Bedeutung besaßen. Man unterschied nicht zwischen Opfern aufgrund ihrer nationalen, religiösen

\footnotetext{
${ }^{1}$ Vgl. allgemein zur Aufarbeitung der NS-Vergangenheit in Deutschland:

Fischer, Lorenz (Hg.) (2007), Lexikon der ,Vergangenheitsbewältigung' in Deutschland. Debatten und Diskursgeschichte des Nationalsozialismus nach 1945.,Bielefeld, Transcript Verlag 2007.

Reichel, Peter (2001) Vergangenheitsbewältigung in Deutschland. Die Auseinandersetzung mit der NS-Diktatur von 1945 bis heute, München, Beck.
} 
oder rassischen Zugehörigkeit. Opfer war Opfer, und so konnten sich auch die Ostdeutschen in die Reihe der Opfer des Hitlerfaschismus eingliedern, was auf lange Sicht $\mathrm{zu}$ einer anderen Gedenkkultur führte. Nicht nur in der Sowjetunion, auch in Ländern wie Frankreich, England oder den USA erhielten die jüdischen Opfer des NS-Regimes zunächst keine gesonderte Aufmerksamkeit. In den Nürnberger Prozessen, beispielsweise, traten sie allenfalls als Zeugen auf, nicht als Opfer, die ihr Leid erzählen sollten, und wurden so zum zweiten Male Opfer (Weigel 2002).

In Westdeutschland kam hinzu, dass man mit Beginn des Kalten Krieges von der Rolle des Besiegten in die eines Verbündeten gegen den Kommunismus wechselte. Schließlich führte auch die Amnestiepolitik Adenauers zu Beginn der 50er Jahre zu einer Art Schlussstrichmentalität - man wollte endlich nach vorne schauen (vgl. Frei 1996, und Friedrich 2007).

Was die dennoch stattfindende Beschäftigung mit der Vergangenheit in diesem Jahrzehnt angeht, so kann man resümieren, dass die öffentliche Geschichte in hohem Maße von beteiligten Zeitzeugen mitbestimmt wurde. Vor allem ehemalige Generäle und hohe Offiziere prägten über ihre Memoiren und wichtige Printmedien die Deutung der Vergangenheit und lieferten den Historikern das erste Material für ihre Arbeit (Bösch, Goschler 2009: 17). So dominierten eher Fragestellungen, warum man den Krieg verloren oder wie man den Widerstand gegen Hitler zu bewerten habe.

Erst die 60er Jahre brachten den Völkermord an den Juden durch die großen Prozesse in Jerusalem und Frankfurt wieder ins Bewusstsein der Öffentlichkeit. Damit wurde eine Entwicklung verstärkt, die bereits mit den Nürnberger Prozessen begonnen hatte: Das Geschichtsbild von der NS-Zeit wurde in der Bundesrepublik und dem westlichen Ausland zunehmend das einer Kriminalgeschichte (vgl. Stolleis, Frei, van Laak 2000). Auch literarische Texte der 60er Jahre sind von dieser Perspektive geprägt, etwa Peter Weiss` Die Ermittlung (1965).

Bei der hier einsetzenden Zusammenarbeit von Historikern und Justiz bedachte man aber nicht, dass das Erkenntnisinteresse von Staatsanwälten und Historikern wesentlich verschieden ist, beschränkt es sich doch bei ersteren strikt auf Handlungen, die gegen das Strafgesetzbuch verstoßen und nicht verjährt sind. Auch der Gegenstand der Untersuchung ist für den Staatsanwalt klarer definiert als für den Historiker: Ermittlungen betreffen die Tat und den Täter; ohne Täter, kein Prozess. Dagegen sind historische Forschungen keineswegs an konkrete Individuen gebunden: "Juristische Wahrheitssuche ist stets personal“ - das hat sie mit der literarischen Geschichtsvermittlung gemeinsam - „wissenschaftliche Erklärungen historischer Wirklichkeiten hingegen sind größtenteils überpersonal“ (Wildt 2000: 52).

Eine solche Rekonstruktion von einzelnen Taten und Ereignissen konnte dazu beitragen, dass eine Mehrheit der Bevölkerung sich durch die gerichtliche Verurteilung von Tätern keineswegs mitbetroffen fühlte: schließlich saßen die 
Schuldigen vor Gericht - und man selber nicht.

Dies mag einer der Gründe dafür sein, dass es erst in den späten 70er Jahren zu einem deutlichen Bewusstseinswandel in der westdeutschen Bevölkerung kam. Die amerikanische Serie „Holocaust“, die dem Völkermord an den Juden den Namen gegeben hat, mit dem wir ihn heute hauptsächlich bezeichnen, kann dafür in ihrer Bedeutung kaum überschätzt werden. Der Spiegel kommentierte die sensationelle Resonanz, die die Ende Januar 1979 in der Bundesrepublik ausgestrahlte Serie hatte, mit den Worten: „Schwarzer Freitag für Historiker". Eine Nation war betroffen - nicht durch ein sorgsam erarbeitetes Geschichtswerk, sondern durch eine sich nur grob an Tatsachen haltende, dafür aber emotional aufwühlende Hollywood-Inszenierung. Für den Leiter des Instituts für Zeitgeschichte, Martin Broszat, bewies dieser Erfolg die enorme „Diskrepanz zwischen Breitenwirkung und Qualität" von geschichtlicher Aufarbeitung sowie „die unbestreitbaren Unzulänglichkeiten der deutschen Zeitgeschichtswissenschaft bei der Behandlung des HolocaustThemas." (Broszat 1979: 285)

Der Erfolg verdankte sich auch einer erschütternden „Kenntnislosigkeit des Fernseh-Publikums", dem auf diese Weise eine "Reihe ereignisgeschichtlicher Komplexe“ offensichtlich „zum erstenmal bekannt" wurde, die von der Geschichtswissenschaft längst aufgearbeitet worden waren - ein Umstand, den Broszat als „normal“ einschätzte, „wenn man in Betracht zieht, daß es sich um 15 Millionen Zuschauer handelte und selbst das erfolgreichste zeitgeschichtliche Buch kaum mehr als einige hunderttausend Leser erreicht." (Broszat 1979: 289)

Es stellte sich also die Frage: Konnte die Aufklärung breiter Bevölkerungsschichten nur durch emotional aufwühlende Spielfilme erreicht werden?

Auch wenn die Wirkung historischer Forschung durch ihre sehr bescheidene Rezeption begrenzt ist, gab es deutlichen Verbesserungsbedarf was die Darstellung der Forschungsergebnisse betraf, denn der Völkermord war bis dahin nur selten eigenständig behandelt worden, meistens wurde er im Rahmen der allgemeinen NS-Geschichte thematisiert, wo zudem die Verbrechen „mehr konstatiert als veranschaulicht" wurden. (Broszat 1979: 296) In der Folge zogen die Historiker daraus ihre Schlüsse: eine Überwindung der Fokussierung auf die Ereignisgeschichte und Täterkonzentrierung und eine Weitung der Forschungsperspektive auf die Frage, wie jene allgemeine moralische Desensibilisierung der deutschen Gesellschaft möglich geworden war, die den Nährboden für die Akzeptanz der Geschehnisse während des Dritten Reiches bildete.

In der zweiten Hälfte der 80er Jahre lösten dann das Buch von Ernst Nolte „Der europäische Bürgerkrieg 1917-1945“ und die Reaktion von Jürgen Habermas jene als ,Historikerstreit' bekannt gewordene öffentliche Debatte aus. Habermas betonte die moralische Einzigartigkeit des Holocaust, seine Kritiker 
wandten ein, dass moralische Kriterien nicht länger der Maßstab der Geschichtsschreibung sein könnten und ein Weg gefunden werden müsse, die Ereignisse der damaligen Jahre im Gesamtzusammenhang der deutschen und europäischen Geschichte zu erzählen, selbst auf die Gefahr hin, sie damit zu „normalisieren“, d.h. ihrer Einzigartigkeit zu berauben.

Zehn Jahre später, nach dem Fall der Mauer, hatte sich die Debatte verschoben: nun ging es darum, wer durch wen in welchem Ausmaß gelitten hatte. Diese Frage hatte lange Zeit als nicht legitim gegolten. In den 80er Jahren wäre es schwer vorstellbar gewesen, dass Günter Grass über die Flüchtlinge an Bord der Gustloff oder Sebald und Friedrich über den Bombenkrieg geschrieben hätten. Nicht etwa weil man darin „unpassende historische Themen“ gesehen hätte, sondern weil „die Vorstellung, das Leid der Deutschen“ zu thematisieren und es damit „,implizit mit dem Leid zu vergleichen, das Deutsche anderen Völkern zugefügt" hatten, in der 80er Jahren "einer Relativierung der Naziverbrechen gefährlich nahe gekommen" wäre (Judt, Snyder 2015: 59f).

Im Unterschied zum sog. Historikerstreit waren in den 90er Jahren vor allem Schriftsteller an der Aufarbeitung der NS-Vergangenheit beteiligt. Dazu gehörten neben vielen anderen:

Bernhard Schlink: Der Vorleser (1995); Martin Walser: Ein springender Brunnen (1998); Dieter Forte: Das Haus auf meinen Schultern (1999); Hans Lebert: Die Wolfshaut (2001); Günther Grass: Im Krebsgang (2002); Uwe Timm: Am Beispiel meines Bruders (2003); Klaus Modick: Der kretische Gast, (2003); Ulla Hahn: Unscharfe Bilder (2003); Arno Surminski: Vaterland ohne Väter (2004); Helga Schneider: Lass mich gehen (2004), Als wir Kinder waren (2005); Kerstin Hensel: Falscher Hase (2005); Walter Kempowski: Alles umsonst (2006); Reinhard Jirgl: Die Stille (2009), Die Unvollendeten (2010).

Dieser Boom setzte sich mit nur kurzer Verzögerung auch in der Filmproduktion fort. Allein zwischen 2001 und 2010 waren in deutschen Kinos oder im Fernsehen, neben vielen anderen, die folgenden Filme über die NS-Zeit $\mathrm{zu}$ sehen (wenngleich es sich nicht bei allen um deutsche Produktionen handelte): So weit die Füße tragen (2001); Der Untergang (2004); Der neunte Tag (2004); Stauffenberg (2004); Napola (2004); Das Goebbels Experiment (2005), Sophie Scholl. Die letzten Tage (2005); Die Hitlerkantate (2005); Die Fälscher (2007); Die Flucht (2007); Am Ende kommen Touristen (2007); Mein Führer - Die wirklich wahrste Wahrheit über Hitler (2007); Der Junge im gestreiften Pyjama (2008); Der Vorleser (2008); Anonyma: Eine Frau in Berlin (2008); Operation Walküre (2008); Die Brücke (2008); Die Gustloff (2008); John Rabe (2009); Inglourious Basterds (2009); Jud Süß - Film ohne Gewissen (2010).

Hinzu kommen zahlreiche Fernsehproduktionen wie der seit 2013 auch international ausgestrahlte Dreiteiler „Unsere Mütter, unsere Väter“ oder der im Januar 2015 gesendete Dreiteiler „Tannbach. Schicksal eines Dorfes“.

Der Kontext, in dem dieser Boom Ende der Neunzigerjahre begann, ist durch mindestens zwei wichtige Aspekte gekennzeichnet. Erstens trat die letzte 
Generation noch lebender Zeitzeugen vor ihrem Ableben mit einem von den Medien intensiv geförderten Erinnerungsbedürfnis an die Öffentlichkeit, und sie tat dies zu einem Zeitpunkt, als in der internationalen Historiografie die Themen kollektives Gedächtnis, Erinnerungskulturen und Kriegstraumata thematisiert wurden. Zweitens bestand ein objektiver Bedarf, die verschiedenen Erinnerungskulturen des geteilten Deutschland nach der Wiedervereinigung zu gemeinsamen Erinnerungsformen und -inhalten zusammenzuführen.

Nicht zu vergessen sind weitere Ereignisse der 90er Jahre wie die Wehrmachtsausstellung, die Goldhagen-Debatte oder das Wiedererstarken rechtsextremer Geschichtsbilder im Internet.

Allgemein kann man sagen, dass in der Belletristik verstärkt die Opfer des Krieges in den Vordergrund gerückt wurden - etwa bei den Themen Flucht und Vertreibung, Vergewaltigung, Bombenkrieg, Holocaust oder Kindheit im Krieg - und dass andererseits, im Kontext der Wehrmachtsausstellung und der Goldhagendebatte, die Kriegsgeneration in ihrer Rolle als Mitläufer, aber auch als Täter auf ihre Schuld hin beleuchtet wurde. Hinzu kam eine oft und deutlich geäußerte literarische Kritik an der akademischen Historiografie (etwa bei Walser, Sebald, Forte und Ruth Klüger).

In der Filmproduktion - sofern es sich nicht um Buchverfilmungen handelte - dominierten andere Themen: die Figur Hitlers und anderer führender Nazis, die Opfer von Holocaust und Vertreibung, die Erinnerung an Widerstandskämpfer und ein generelles Bedürfnis nach positiven Helden.

Während die Geschichtswissenschaft in den 50er Jahren zunächst vor allem Militärgeschichte und in der Folge, durch die Aufarbeitung der Geschichte vor Gericht, im Wesentlichen Täter- und Ereignisgeschichte war, trat sie in den 80er Jahren vor allem als Sozial- und Alltagsgeschichte, als ,Oral History' und durch den Historikerstreit ins Bewusstsein der Öffentlichkeit. Aber seit der ,Holocaust'-Serie und vor allem seit den 90er Jahren wurde der Geschichtswissenschaft ihre Deutungshoheit streitig gemacht, und zwar durch etwas, das man im angelsächsischen Sprachraum ,Public history` nennt: die Schaffung von Geschichtsbildern durch Spielfilme, Dokumentarfilme, Literatur und andere Formen nicht-akademischer Darstellung von Geschichte in der Öffentlichkeit (vgl. Bösch, Goschler 2009).

Dies zeigt sich auch in eben jenem Boom, den wir seit den 90er Jahren beobachten können und der die Gefahr birgt, vor lauter Geschichten die Geschichte aus dem Blick zu verlieren. Hatte Jacob Burckhardt einst noch auf eine Überwindung der Emotionen durch die rationale Geschichtsschreibung gehofft $^{2}$, so erleben wir zu Beginn des 21. Jahrhunderts eher eine Reemotionalisierung der Geschichte durch ihre Auflösung in Geschichten.

Nimmt man alle Formen der Geschichtsaufarbeitung zusammen, so lässt sich bis zur Jahrtausendwende und darüber hinaus festhalten, was Micha

\footnotetext{
2 „Was einst Jubel war und Jammer, muß nun Erkenntnis werden“. (Burckhardt 1950: 31)
} 
Brumlik 2001 im Vorwort zum Lexikon der "Vergangenheitsbewältigung" in Deutschland so formulierte:

\begin{abstract}
Man übertreibt nicht, wenn man behauptet, dass es derzeit und vermutlich auch in alle Zukunft (...) keine andere Gesellschaft gegeben hat oder geben dürfte, die den Opfern von Staatsverbrechen ein Mahnmal gesetzt hat wie jenes, das nach Jahren heftiger Auseinandersetzung vor dem deutschen Parlament, vor dem ehemaligen Reichstagsgebäude in der Hauptstadt Berlin errichtet wurde. Man versuche sich nur einmal vorzustellen, dass in Ankara ein Denkmal für die Toten des jungtürkischen Genozids an den Armeniern oder in Moskau ein Mahnmal an die Opfer des GULAG errichtet würde. Darauf stolz zu sein und sich der damit verbundenen politischen Ethik verpflichtet $\mathrm{zu}$ sehen, wäre (jungen) Bundesbürgern nicht unangemessen. (Fischer, Lorenz 2007: 10)
\end{abstract}

\title{
2. VOM GUTEN SINN DER LITERARISCHEN AUFARBEITUNG EINER NEGATIVEN VERGANGENHEIT
}

Zur Geschichte der Bundesrepublik Deutschland gehört wesentlich die Geschichte ihrer Auseinandersetzung mit der NS-Vergangenheit. Ihr politisches Selbstverständnis beruht darauf, aus dem Leid, das der Nationalsozialismus über Deutschland, Europa und die Welt gebracht hat, zu lernen und in Zukunft gerade die Werte und Rechte zu verteidigen, die zwischen 1933 und 1945 mit Füßen getreten wurden. Eine "negative Erinnerung" ist also keineswegs mit einem "negativen Selbstbild“ gleichzusetzen, sondern in "positive und zukunftsweisende Werte konvertierbar" (Assmann 2006: 279). Darin besteht der Sinn der Erinnerungskultur in Deutschland.

Dennoch wurde die angesprochene politische Ethik, die auf dem Respekt vor der Wahrheit und den Menschenrechten gründet, von Anfang an und bis in die Gegenwart immer wieder durch eine nationalistische und/oder rechtsradikale Kritik in Frage gestellt, welche die von sog. "Nestbeschmutzern" betriebene Aufklärung der Verbrechen - und nicht etwa die Verbrechen selber - für die "nationale Schande“ verantwortlich macht. Noch im Januar 2017 beklagte der AfD-Politiker Björn Höcke in einer Rede vor der eigenen Parteijugend in Dresden: „Wir Deutschen [...] sind das einzige Volk der Welt, das sich ein Denkmal der Schande in das Herz seiner Hauptstadt gepflanzt hat. ${ }^{\text {3 }}$

Solange die Mehrheit der Gesellschaft und vor allem der Jugend "stolz" ist auf diesen, mit nicht unerheblichen psychischen Kosten verbundenen, kathartischen Akt politischer Selbstreinigung - oder sich zumindest damit identifiziert - ist eine wesentliche Bedingung dafür erfüllt, dass die

3 Der Redeausschnitt ist zu sehen unter: https://www.youtube.com/watch?v=7E_Mvgsk6PY (letzter Aufruf am 9.11.2018). Der Wortlaut der Rede ist nachzulesen unter: https://www.tagesspiegel.de/politik/hoecke-rede-im-wortlaut-gemuetszustand-eines-totalbesiegten-volkes/19273518-all.html (letzter Aufruf am 9.11.2018). 
Bevölkerung in Deutschland weiterhin im Genuss einer freiheitlichen und demokratischen Grundordnung leben kann - und das ist mitnichten eine Selbstverständlichkeit, wie die jüngere und jüngste deutsche und europäische Geschichte zeigt.

Auf der anderen Seite hat sich bei der Aufklärung und Aufarbeitung dieser Vergangenheit immer wieder gezeigt, dass sie leider allzu häufig, vereinzelt oder sogar kollektiv, mit moralischer Selbstgefälligkeit und einem gefährlichen Eifer des Verurteilens Hand in Hand geht. Bernhard Schlink hat diesen Aspekt in seinem Bestseller Der Vorleser als einer der Ersten literarisch aufgearbeitet:

Aufarbeitung! Aufarbeitung der Vergangenheit! Wir Studenten des Seminars sahen uns als Avantgarde der Aufarbeitung. Wir rissen die Fenster auf, ließen die Luft herein, den Wind, der endlich den Staub aufwirbelte, den die Gesellschaft über die Furchtbarkeiten der Vergangenheit hatte sinken lassen. (...) Auch wir setzten nicht auf juristische Gelehrsamkeit. Dass verurteilt werden müsse, stand für uns fest. Ebenso fest stand für uns, dass es nur vordergründig um die Verurteilung dieses oder jenes KZ-Wächters und -Schergen ging. Die Generation, die sich der Wächter und Schergen bedient oder sie nicht gehindert oder sie nicht wenigstens ausgestoßen hatte, stand vor Gericht. (Schlink 1997: 87)

In Schlinks Buch werden einige fragwürdige Motive der Aufarbeitung seit den sechziger Jahren kritisch in den Blick genommen: wo der Eifer des Anklagens und die Wut des Verurteilens Ausdruck eines Generationskonfliktes sind, geht es nicht mehr in erster Linie um die Wahrheit. Es hat eher schon etwas von der Logik der Denunziation: nur wer Andere anklagt steht selber (scheinbar) auf der richtigen Seite der Moral. Indem man auf Andere mit dem Finger zeigt, versucht man selber mit seinem Gewissen ins Reine zu kommen.

Im Vorleser geht es um Verurteilen und Verstehen. Verurteilen sollte auf Verstehen gründen, und diese beiden gegenläufigen Denkbewegungen - die der Distanzierung von der moralischen Verfehlung und die der Annäherung an die Bedingungen ihrer Möglichkeit - sind zwar schwierig zu vereinen, aber es handelt sich dennoch um eine unverzichtbare Anstrengung.

Dass diese Anstrengung aber mitnichten eine Selbstverständlichkeit darstellt, zeigte eine heute schon fast in Vergessenheit geratene Literaturdebatte kurz nach der Jahrtausendwende. In Ihren Ausgaben vom 30. März, 20. und 27. April 2002 versuchte die Süddeutsche Zeitung den Vorleser als „Kulturpornographie" und "Holokitsch", als abscheulich und unmoralisch gewissermaßen auf den Index der politisch unkorrekten Bücher zu setzen. Als Vorwand diente dabei ein Streit, der angeblich unter „britischen Schriftstellern und Literaturwissenschaftlern" "entbrannt" sei. (SZ 27.4.2002, S.16).

Tatsächlich hatte es im britischen Times Literary Supplement - neben lobenden Kritiken - im März 2002 auch drei Leserbriefe gegeben, die sich über den acht Jahre zuvor erschienen Roman empörten. In der SZ kamen diese Kritiker nun ausführlich zu Wort - die Fürsprecher nicht. Die Titel zeigen 
bereits die Leitideen an, unter denen das Buch im Feuilleton behandelt wurde. Lawrence Norfolk versuchte zu zeigen, „Warum (...) ,Der Vorleser' ein so schlechtes Buch ist", Jeremy Adler, Sohn eines Holocaust-Überlebenden, erhob Einspruch gegen "Die Kunst, Mitleid mit den Mördern zu erzwingen" und Tanja Dückers erklärte auf derselben Seite mit Bezug auf Schlink, „Warum die ,Enkelgeneration' nach dem Zweiten Weltkrieg noch nicht zum, entspannten Umgang' mit der Vergangenheit geneigt ist."

Damit war das Stichwort gefallen, worum es in Wirklichkeit ging: um den als ,angemessen' erachteten Umgang mit der Vergangenheit. Das wiederum weckte die Vermutung, dass die literarischen Aspekte des Vorlesers gar nicht der eigentliche Gegenstand der Kritik seien, sondern allenfalls ein Vorwand. Der Spiegel bestätigte dies sogleich in seiner Ausgabe vom 9. April 2002. Unter dem Titel „Autoren unter Generalverdacht“ hieß es dort: „Kulturkritiker rüsten zu einer bizarren Literaturdebatte: Verharmlosen erfolgreiche Bücher wie Günter Grass' Novelle Im Krebsgang oder Bernhard Schlinks Roman Der Vorleser die Schuld der Deutschen am Holocaust und am Zweiten Weltkrieg?"

Was den genannten Autoren, oder auch Schriftstellern wie Peter Schneider und Dieter Forte, zwar nicht nachgewiesen, aber in vorausgreifender Erfassung der eigentlichen Autorintention unterstellt wurde, war eine "Transformation der Täter- in eine Opfergesellschaft" (Neue Zürcher Zeitung) und eine "Entlastung der Deutschen von ihrer Schuld“ (Süddeutsche Zeitung). Der Spiegel resümierte, es habe „seit den Tagen der DDR keine derart ideologischen Gutachten über deutsche Literatur gegeben." 4

Tatsächlich war und ist der Umgang mit der deutschen NS-Vergangenheit stets auch eine Frage ideologischer Positionierung, und vielleicht ist das teilweise auch unvermeidlich, wenn der Sinn der deutschen Erinnerungskultur in der Transformation einer negativen Vergangenheit in eine bessere Zukunft bestehen soll.

Aber die Frage, um die im Kern die meisten Diskussionen dieser Art kreisen, ist weniger eine Frage der Werte - immerhin standen bis in die allerjüngste Gegenwart alle beteiligten Autoren, Filmemacher, Intellektuelle und Politiker ohne Wenn und Aber zu den Werten des Grundgesetzes -, sondern es geht um das dramaturgische Austarieren des Spielraumes unserer Phantasie: wie weit dürfen wir uns in die psychologische und moralische Lage fiktionaler oder historisch realer Akteure der NS-Zeit hineinversetzen, ohne unseren eigenen Standpunkt zu verlieren? Wieviel Verständnis dürfen wir für eine andere Zeit mit anderen Anschauungen aufbringen, ohne den Maßstab zu verlieren, was es zu verurteilen gilt? Wie lässt sich dem Trugschluss entgehen, alles $\mathrm{zu}$ verstehen heiße alles zu verzeihen?

\footnotetext{
${ }^{4}$ Harald Welzer: Zurück zur Opfergesellschaft, Neue Zürcher Zeitung, Ausgabe vom 4. April 2002; Volker Hage: Autoren unter Generalverdacht, Der Spiegel, Ausgabe vom 9. April 2002.
} 
Wo solche Fragen von vornherein verdrängt werden, da sollte man nicht von pädagogischer Aufarbeitung, sondern von einer ,Entsorgung' der Vergangenheit sprechen, die traditionell ihr Vorbild in Hollywood sucht: vom Bösen distanziert man sich durch Verlachen oder durch Dämonisierung. Und durch Identifikation mit den Guten. Dass die Guten dabei Jahrzehnte lang die Amerikaner waren, ist allenfalls ein kleiner Kollateralschaden der Geschichtsschreibung durch die Sieger. Das eigentliche Problem besteht darin, dass dieses auf einem schwarz-weiß-Schema von Gut und Böse beruhende Geschichtsbild allenfalls zu Abwehrautomatismen und -Reflexen erzieht, die exakt lange funktionieren, wie die heutige Realität der in den Massenmedien dargestellten Fiktionalität ähnelt, uns aber in keiner Weise über die Entstehungsbedingungen des Bösen oder Destruktiven in der eigenen Psyche und über situativ bedingte Verhaltens-dynamiken aufklärt.

So kommt es denn, dass nachfolgende Generationen sich oft reflexartig in einer moralisch überlegenen Position gegenüber der Vergangenheit schlechthin wähnen, ohne dabei wirklich etwas über moralische Dilemmata, Hinterfragung von Massenmanipulation und existenzielle Entscheidungen gelernt zu haben.

Statt zu Reflexen und Automatismen sollte die Beschäftigung mit der Vergangenheit vielmehr zu einer Reihe von, für die eigene Identität spannenden, Fragen einladen: Wie hätte ich mich damals verhalten? Und gleichzeitig muss man rasch über diese Frage hinauskommen, denn sie lässt sich nicht beantworten: das heutige Bewusstsein ist ja nicht identisch mit einem fiktiven Ich in den dreißiger oder vierziger Jahren. Man kann also nur sagen, wie man sich aus heutiger Sicht wünscht, gehandelt $\mathrm{zu}$ haben, was $\mathrm{zu}$ der nächsten Frage führt, wo denn die Verantwortung des Einzelnen beginne, ob etwa Kindersoldaten schuldig seien oder ob Jugendliche, die durch Schule und Gesellschaft im Sinne einer menschenverachtenden Ideologie erzogen werden, für ihre Erziehung und die daraus entstehenden Konsequenzen verantwortlich seien. Anders gefragt, gibt es eine Stimme in uns, die deutlich das Gute vom Bösen unterscheiden kann? Und wenn es ein solches Gewissen gibt, ist es anerzogen, gott- bzw. naturgegeben oder selbst geformt? Und welche Freiheit hat ein solches Ich, so zu werden, wie es eigentlich sein möchte? Hat es die Freiheit, sich stets am Guten zu orientieren?

Der Sinn solcher Fragen und folglich der Beschäftigung ausgerechnet mit dieser Vergangenheit erhellt vielleicht am besten aus der Kantschen Bestimmung des Menschen als eines Wesens, das Fragen stellen und Antworten suchen muss - sozusagen als anthropologisch-kulturelle Selbstverwirklichung.

Hinter den drei Kantschen Fragen: was kann ich wissen, was soll ich tun, was darf ich hoffen, steht im Kern eine einzige Grundfrage: Was ist der Mensch? Und Kants Antwort auf diese Frage lautet: Der Mensch ist ein Wesen, das sich Fragen stellen muss, die es nicht beantworten kann. Für Kant sind es die Fragen nach der Existenz Gottes, nach der Freiheit des eigenen Willens und nach der Unsterblichkeit der Seele. Laut Kant muss sich unsere Vernunft diese 
Fragen stellen, obwohl sie zu endlich und zu beschränkt ist, um sie letztlich beantworten zu können. Dabei ist der Raum jenseits dessen, was wir wissen können, der Raum, der die transzendenten Fragen betrifft, und unsere Freiheit resultiert gerade daraus, dass wir die entscheidenden transzendentalen Antworten nicht wissen können. Darum muss Literatur, muss Fiktionalität uns immer wieder $\mathrm{zu}$ Antworten provozieren, die wir eigentlich nicht geben können: wie hätte ich mich verhalten? Und: wie hätte ich mich verhalten sollen?

Auch die Frage der Schuld, um die es im Vorleser geht, gehört zu den Fragen, deren letzter Sinn in Selbsterkenntnis und Ich-Konstitution besteht und es ist genau darum eine der zentralen Kategorien im Umgang mit der NSVergangenheit. Aber leider haben sich Film und Literatur nur selten in anspruchsvoller und wenig ideologischer Weise auf diese Problematik eingelassen.

Angesichts der bereits erwähnten Fülle von privaten, literarischen und journalistisch recherchierten Erinnerungen, von Helden- und Opfergeschichten, von Filmgenres wie dem Hitler- und dem Holocaust-Filmgenre, die sich alle um die Frage von Schuld, Verstrickung und Widerstand drehen, lohnt es sich, einmal einen Blick zurück zu werfen, um die Literatur unmittelbar nach Kriegsende, das heißt noch vor Gründung der beiden deutschen Staaten, nach ihrem Wissen über die NS-Zeit zu befragen und zu prüfen, ob sie Erfahrungen vermittelt, die in späteren Erinnerungsdiskursen verloren gegangen sind.

Bei den Werken, die zu diesem Zweck untersucht werden, handelt es sich um drei Theaterstücke und eine Erzählung: C. Zuckmayers Des Teufels General (1946), W. Borcherts Draußen vor der Tür (1946), M. Frischs Nun singen sie wieder (1946), und A. Goes' Unruhige Nacht (1949). Was diese, unter sich so verschiedenen Werke, miteinander verbindet, ist, über die zeitliche Nähe ihres Erscheinens und die zeitliche Unmittelbarkeit $\mathrm{zu}$ ihrem historischen Bezugspunkt hinaus, vor allem die diesen Werken gemeinsame Thematik der Unentrinnbarkeit der Schuld.

\section{DiE SCHUldFrage IN DER DeUTSCHEN LiteratUR UNMITTElbaR NACH KRIEGSENDE}

\subsection{Carl Zuckmayer Des Teufels General}

Carl Zuckmayer schrieb Des Teufels General noch während des Krieges in seinem amerikanischen Exil, auf einer abgelegenen Farm im Bundesstatt Vermont. Die Idee zu diesem Stück nahm ihren Ausgang von einer Zeitungsmeldung aus dem Jahr 1941, der Zuckmayer entnahm, dass sein Freund Ernst Udet, der zusammen mit Manfred von Richthofen eines der beiden großen Jagdfliegeridole aus der Zeit des Ersten Weltkriegs und im Zweiten Weltkrieg Generalluftzeugmeister der Wehrmacht war, beim 
Ausprobieren einer neuen Waffe tödlich verunglückt sei. ${ }^{5}$ Später schrieb Zuckmayer in seiner Autobiografie Als wär's ein Stück von mir: „Was in Wirklichkeit vorgegangen war, wusste ich nicht, und es kümmerte mich nicht. Die Tragödie stand mir vor Augen - lückenlos." (Zuckmayer 1969: 451)

Sie bestand für Zuckmayer darin, dass jemand, auf den er große Stücke hielt, sein Können auf einem Gebiet zur Meisterschaft gebracht hatte, das ab 1933 von den Nazis kontrolliert wurde und der nun vor der Wahl stand, alles aufzugeben, was er bis dahin erreicht hatte oder sich in den Dienst des NSRegimes zu stellen und so, über den Ruhm hinaus, auch zu Macht und Einfluss zu gelangen. Vor diese Frage sahen sich übrigens die meisten Leistungsträger und Spitzenkräfte in Wirtschaft, Wissenschaft, Sport, Unterhaltungsindustrie usw. gestellt, wenn sie nicht emigrieren mussten, weil sie, wie Hannah Arendt es provokativ formulierte, „entweder das Glück hatten, Juden zu sein oder rechtzeitig von der Gestapo verfolgt zu werden, [und so] von dieser Schuld [des Mitmachens] bewahrt worden sind“. (Arendt 1946: Fußnote S. 339).

Der Inhalt des Stückes ist schnell erzählt. Der mit jugendlichem Charme ausgestattete schneidige Draufgänger Harras, nutzt, obwohl er die Nazis öffentlich verhöhnt, die Karrierechancen, die ihre Kriegspolitik und der Krieg ihm bieten. Nachdem aufgrund von Sabotage wiederholt Flugzeuge abgestürzt sind, wird der Kreis der Verdächtigen im Verantwortungsbereich von General Harras gesucht, der zunächst glaubt, dass die Gestapo und die SS die Unglücksfälle inszeniert hätten, um ihn zu vernichten. Doch schließlich gesteht ihm sein Freund Oderbruch, hinter den Sabotageakten zu stehen. Im Gespräch mit Oderbruch widersteht Harras sowohl der Versuchung, sein Leben durch die Preisgabe des Schuldigen zu retten, als auch dessen Vorschlag, im Ausland für die Widerstandbewegung zu arbeiten. Er unterzeichnet den Untersuchungsbericht und deckt damit Oderbruchs Handlungen, obwohl er sie nicht billigt. Mittlerweile an Einsicht soweit gereift, dass er seine aktive Mittäterschaft an diesem Krieg als Schuld begreift, steigt er in eines der durch Sabotage manipulierten Flugzeuge und wählt den freiwilligen Sühnetod: „Wer auf Erden des Teufels General wurde und ihm die Bahn gebombt hat - der muss ihm auch Quartier in der Hölle machen." (Zuckmayer 1973: 154)

Der Fliegergeneral Harras ist schuldig, seine Talente in den Dienst des Bösen gestellt zu haben. Aber auch sein Antipode, der Idealist Oderbruch, ist schuldig, indem er für seinen Widerstand gegen das Regime eine Form wählt, bei der nicht die Entscheidungsträger, sondern einfache Frontsoldaten

\footnotetext{
${ }^{5}$ Das entsprach der offiziell verbreiteten Version. Dass es sich in Wirklichkeit um den Suizid eines im Reichsluftfahrtministerium gescheiterten Fliegers (so sah Udet sich selber) handelte, der mitverantwortlich war für die fehlgesteuerte deutsche Luftrüstung der ersten Kriegsjahre, musste der Öffentlichkeit vorenthalten werden, denn Udet war eine der prominentesten Propagandafiguren des NS-Staates. Das Bild des vorbildlichen Helden wurde durch das von Hitler angeordnete Staatsbegräbnis bis zum letzten Moment aufrechterhalten, denn Zweifel an diesem Bild hätten zwangsläufig Zweifel an der Sache, für die er tätig war, aufkommen lassen.
} 
hingeopfert werden.

Aber nicht nur die beiden Hauptfiguren, auch die meisten anderen Figuren des Stücks sind auf die eine oder andere Weise mit Schuld beladen. Da sind zunächst die Kollaborateure um des eigenen Vorteils willen: der Präsident des Beschaffungsamtes für Rohmetalle, Sigbert von Mohrungen, der zu den Industriellen gehört, die die Nazis finanziert haben und Baron Pflungk, der trotz seiner Verachtung der plebejischen Nazis mit diesen kollaboriert, um seine Stellung und Einkünfte nicht zu gefährden. Dann die eigentlich bösen Figuren: Pützchen von Mohrungen und Dr. Schmidt-Lausitz. Pützchen, die im NS-Regime vor allem eine Chance sieht, ihre Karriere- und Machtwünsche zu erfüllen, ist vielleicht die dämonischste Figur des ganzen Stücks, denn sie verkörpert, unter zynischer Verachtung aller Moral, die pure Besessenheit nach Macht. Ein ganz anderer Typ als Pützchen ist die lehmurisch-böse Schattengestalt des Dr. Schmidt-Lausitz, überzeugter Nationalsozialist und von Neid und Ehrgeiz getriebener unmenschlicher Gegenspieler von Harras. Erst vor dem Hintergrund dieser beiden Gestalten wird die besondere Dämonie des Generals Harras deutlich: Er verkörpert sozusagen eine „altmodische Dämonie, zumindest im Zeitalter der Vermassung und Entpersönlichung", denn gerade, weil er ein Mann von "Format ist, durfte er die Sache“ jener "niederen Dämonen“ „niemals zu der seinen machen.“ (Müller-Gangloff 1949) Und schließlich gibt es im Stück noch den Typus der Verführten: Leutnant Hartmann sowie Friedrich und Anne Eilers. Sie folgen Hitler mit ahnungslosem Idealismus, doch auch sie können ihre Hände nicht in Unschuld waschen, wie Harras Anne entgegenhält:

Können Sie denn selbst vor Ihrem Richter stehn - und sagen: das Gute hab ich gewollt, das Böse nicht gewusst? Wie konntet ihr denn je an eine Sache glauben, deren Schlechtigkeit uns an jeder Straßenecke in die Augen springt? Wie durftet ihr von Idealen reden, wenn ihr die Visagen derer seht, die sie vertreten? Die hier nicht wissen - die wollen nicht wissen - und die dennoch glauben, die machen sich was vor. (Zuckmayer 1973: 145).

Zuckmayers Drama zeigt also die individuellen Verstrickungen in eine historische Schuld, die selbst noch die Gegner des NS-Regimes erfasst und verdeutlicht damit die Schwierigkeit, sich in einer geschichtlichen Katastrophensituation „richtig“ zu verhalten. So zeichnet das Stück das Bild einer Gesellschaft, die sich mehrheitlich in unterschiedlichen Graden der Mittäterschaft schuldig gemacht hat. Der Erfolg des Stücks beruht dabei auf dem Scheitern einer mit Haltung und vorbildlicher Männlichkeit ausgestatteten Identifikationsfigur, die als Idol einer ganzen Epoche entzaubert wird und so einen kathartischen Selbstläuterungsprozess im Publikum bewirkt: so wie er wollten wir gerne sein und darum konnte geschehen, was geschah. 


\subsection{Wolfgang Borchert Draußen vor der Tür}

Als Wolfgang Borchert 1941 an die Ostfront geschickt wurde, war er zwanzig Jahre alt. Das folgende Jahr verbrachte er im Lazarett, in Untersuchungshaft wegen des Verdachts auf Selbstverstümmelung, in verschärfter Haft wegen staatsfeindlicher Äußerungen und ab Dezember 1942 erneut an der Ostfront. Und so ging es in den beiden folgenden Jahren weiter: Lazarette, Feststellung der Dienstuntauglichkeit, Gefängnis wegen "Zersetzung der Wehrkraft", „Strafaufschub zwecks Feindbewährung“, Fronteinsatz im Westen. Als er 1945 bei Frankfurt a. M. durch französische Truppen gefangen genommen wird, flieht er und schlägt sich in nächtlichen Fußmärschen bis in seine Heimatstadt Hamburg durch, wo er zwei Tage nach Kriegsende ankommt. Er hat die Gelbsucht und Fieberanfälle, träumt dennoch von einer Zukunft auf der Bühne des Theaters, aber sein Gesundheitszustand unterbindet solche Wünsche und fesselt ihn ans Bett. Im Herbst 1946 schreibt er in wenigen Tagen das Stück Draußen vor der Tür, das der NWDR am 13. Februar 1947 sendet. Die Uraufführung des Stücks in den Hamburger Kammerspielen am 21. November 1947 erlebt er nicht mehr, er stirbt am Tag davor im St. Clara Hospital in Basel.

Helmut M. Braem erinnerte sich an die Resonanz, die das Hörspiel Draußen vor der Tür auslöste:

Das war ,unser' Autor. Er hatte etwas ausgesprochen, was wir empfanden, aber nicht zu formulieren verstanden. Und wir, die aus dem Krieg heimgekehrten Beckmänner, haben geweint vor dem Lautsprecher eines aus den Trümmern geretteten ,Volksempfängers' ${ }^{6}$

Mit dem Protagonisten Beckmann hatte Borchert eine Identifikationsfigur geschaffen für die Generation der jungen Frontsoldaten, die sich durch den Krieg und den dafür verantwortlichen Nationalsozialismus um ihre Jugend betrogen und die Gesamtheit ihrer Lebensideale verraten fühlte. Das Stück beginnt so:

Ein Mann kommt nach Deutschland.

Er war lange weg, der Mann. Sehr lange. Vielleicht zu lange. Und er kommt ganz anders wieder, als er wegging. Äußerlich ist er ein naher Verwandter jener Gebilde, die auf den Feldern stehen, um die Vögel (und abends manchmal auch die Menschen) zu erschrecken. Innerlich - auch. Er hat tausend Tage draußen in der Kälte gewartet. Und als Eintrittsgeld musste er mit seiner Kniescheibe bezahlen. Und nachdem er nun tausend Nächte draußen in der Kälte gewartet hat, kommt er endlich doch noch nach Hause.

Ein Mann kommt nach Deutschland. (Borchert 2007: 118)

Anders als die meisten der damals aufgeführten Heimkehrerstücke vollzieht Borchert eine existenzielle und radikale Destruktion aller Illusionen in Bezug auf eheliche Treue, Offiziersethos, kulturelle Erneuerung und allgemeine

${ }^{6}$ Zitiert in Töteberg 2007: 548. 
Mitmenschlichkeit. Das Stück ist mit seiner nihilistischen, existenziellen Desillusion Ausdruck eines Lebensgefühls weiter Teile seiner Generation. Es ist auch Ausdruck einer umfassenden Anklage gegen die Generation der Älteren, wie die Schlusszeilen deutlich machen:

\author{
Wohin sollen wir denn auf dieser Welt? Verraten sind wir. Furchtbar verraten. (...) Wo ist \\ denn der alte Mann, der sich Gott nennt? Wo seid ihr denn alle? Warum redet ihr denn \\ nicht! \\ Gebt doch Antwort! \\ Warum schweigt ihr denn? Warum? \\ Gibt denn keiner Antwort? \\ Gibt keiner Antwort???
}

Gibt denn keiner, keiner Antwort??? (Borchert 2007: 118)

Vor allem auch durch seinen frühen Tod wurde Borchert schnell zu einem Mythos. Bis heute ist er in den Schulbüchern vertreten und gilt als der repräsentative Autor der sog. „Stunde Null“. Aber gegen den Mythos Borchert wurden bald Einwände laut. Viele hielten ihn für zu sehr zeitbedingt und überschätzt. Der Haupteinwand gegen sein Stück Draußen vor der Tür besteht aber bis heute darin, dass er weder die Naziverbrechen, noch die Kriegsschuld oder den Holocaust thematisiert hat. Man kann dem entgegenhalten, dass es nicht die Aufgabe eines einzelnen Theaterstücks sein kann, all diese Themen aufzuarbeiten und vor allem, dass das Anliegen Borcherts ein anderes war, welches auch seine Berechtigung hatte. Dennoch bleibt richtig: das Gefühl, sich verraten zu fühlen, das Borchert mit seinem Stück zum Ausdruck bringt, entsprach einer damals allgemein verbreiteten Neigung, sich als Opfer zu fühlen, als Opfer des Nationalsozialismus und einer verbrecherischen Regierung, die das Land in den Untergang geführt hatte, und diese Perspektive, so verständlich sie sein mochte, ist ethisch unaufrichtig, wenn sie den Blick ausblendet auf das Unheil, das Deutschland über die ganze Welt gebracht hatte. Um es noch härter zu sagen: die Erfahrung, verraten und betrogen worden zu sein, ist unbedeutend angesichts der Millionen Toten in aller Welt. Dass Borchert sich dessen aber durchaus bewusst war, zeigen Äußerungen wie diese: „Was sind wir für ein Volk! Erst treten wir die anderen, aber wenn wir wiedergetreten werden, dann ist der Jammer groß! ${ }^{\prime 7}$

Dennoch bietet auch das Stück selber unter dem Aspekt der Schuldfrage einen interessanten Ansatzpunkt. Borchert schrieb nicht nur gegen das Vergessen und das Bedürfnis, nach vorne zu schauen, er schrieb nicht nur

\footnotetext{
${ }^{7}$ Zitiert in Töteberg 2007: 553.
} 
gegen das, was er einen „billigen Positivismus"8 nannte, d.h. jene Unempfindlichkeit gegen moralische Verzweiflung, die dem Motto Hauptsache $d u$ lebst entsprang, er erinnerte auch an das eigene Schuldig-Werden:

Das ist das Leben! Ein Mensch ist da, und der Mensch kommt nach Deutschland, und der Mensch friert. Der hungert und der humpelt! Ein Mann kommt nach Deutschland! Er kommt nach Hause, und da ist sein Bett besetzt. Eine Tür schlägt $\mathrm{zu}$, und er steht draußen. (Borchert 2007: 190f.)

Da, als er sich ins Wasser stürzen will, in der tiefsten Verzweiflung, kommt ein Mädchen und bietet ihm etwas menschliche Zuneigung an. Und er geht mit dem Mädchen auf ihr warmes Zimmer - wer wollte es ihm verübeln? und bereitet so, ohne es zu wissen, einem Anderen den gleichen Schmerz, der ihn soeben fast in den Tod getrieben hätte:

(...) das Mädchen hat einen Mann, der hat nur ein Bein und der stöhnt andauernd einen Namen. (...) Ein Mann kommt nach Deutschland! Und dann kommt der Einbeinige - teck - tock - teck - kommt er, teck - tock, und der Einbeinige sagt: Beckmann. Sagt immerzu: Beckmann. (...) Und der Mörder bin ich. Ich? Der Gemordete, ich, den sie gemordet haben, ich bin der Mörder? Wir werden jeden Tag ermordet, und jeden Tag begehn wir einen Mord! (Borchert 2007: 191)

Hier wird einer - darf man sagen: schuldlos? - schuldig. Opfer und Täter zugleich. Das ist keine billige Entlastungsstrategie, es ist ein existenzielles Dilemma, hinter dem eine Reihe von, den Autor bedrängenden, Fragen stehen: Was ist der Mensch? Was ist sein Weg? Welchen Sinn hat das Leben? Welche Bedeutung der Tod?

Um diese Fragen geht es letztlich in den Dialogen zwischen Beckmann und dem "Anderen", der immer wieder versucht, mit seinem lebenstüchtigen "Positivismus" den Protagonisten vor dem Suizid zu bewahren und ihn überzeugen, ja fast bekehren will: „Du kennst die Menschen nicht. Sie sind gut." (Borchert 2007: 178)

Die 5. Szene ist eine radikale Destruktion dieses anthropologischen Optimismus: eine nach der anderen treten die Figuren des Stücks noch einmal auf, um diesen Glauben auf die Probe zu stellen, und eine nach der anderen versagt. Nicht, dass sie von Natur aus böse wären. Sie sind einfach "Marionetten", „groteske, karikierte Marionetten“ (Borchert 2007: 184), die von den moralischen Anforderungen, die an sie gestellt werden, schlicht überfordert sind, vor allem auch, weil sie in erster Linie nur an sich selber denken. Die die Menschen an privilegierter Stelle hineingeführt haben, in diesen Krieg, kommen auch an privilegierter Stelle aus ihm wieder heraus. Keine Rede mehr von Volksgemeinschaft, jeder ist sich selbst der Nächste. Der Oberst kurz und knapp über Beckmann: „einer von denen, die sowieso vor die Hunde gegangen wären." (Borchert 2007: 180)

\footnotetext{
8 Zitiert in Töteberg 2007: 549.
} 
Aber: Überleben heißt schuldig werden! Auf diese rigorose ethische Schlussfolgerung werden wir bei Karl Jaspers zurückkommen. Auch Beckmann ist davon nicht ausgenommen, wie ihm der Einbeinige deutlich macht:

Wir werden jeden Tag ermordet und jeden Tag begehen wir einen Mord. Wir gehen jeden Tag an einem Mord vorbei. Und du hast mich ermordet, Beckmann. Hast du das schon vergessen? Ich war doch drei Jahre in Sibirien, Beckmann, und gestern Abend wollte ich nach Hause. Aber mein Platz war besetzt - du warst da, Beckmann, auf meinem Platz. Da bin ich in die Elbe gegangen, Beckmann, gleich gestern Abend. (...) Ich hätte nicht nach Hause kommen dürfen. Zu Hause war kein Platz mehr für mich, Beckmann, denn da warst du. Ich klage dich nicht an Beckmann, wir morden ja alle, jeden Tag, jede Nacht. Aber wir wollen doch unsere Opfer nicht so schnell vergessen. (Borchert 2007: 189f.)

Hier hat ein junger Autor vor seinem Erfahrungshorizont versucht, radikal mit sich und seiner Zeit ins Gericht zu gehen, Anklage und Selbstanklage vorbringend. Er hat Gott, der Religion und allem Gutmenschentum abgeschworen und fragt sich, was mit ihm und seiner Generation geschehen ist. Und er kommt resigniert zu dem Ergebnis, dass er bzw. sein Protagonist - auch nicht besser ist, als die, von denen er sich enttäuscht abwendet.

\subsection{Max Frisch Nun singen sie wieder}

Das Theaterstück, das den Untertitel Versuch eines Requiems trägt, entstand im Januar 1945, wurde am 29.3.1945, also noch während des Krieges, in Zürich uraufgeführt, und schon während der Spielzeit 1946/47 in München und Hamburg auf die Bühne gebracht.

Das Stück ist in zwei Teile aufgeteilt. Dabei stellen die Bilder des ersten Teils noch durchaus realistische Dialogszenen dar, während sich der zweite Teil von einer realistischen Darstellung vor allem dadurch entfernt, dass es zu einer szenischen Durchdringung der Welt der Toten und der der Lebenden kommt, wobei die Totenwelt den Lebenden verschlossen bleibt, während die Toten durchaus Anteil an den Gesprächen der Lebenden nehmen können.

Dieser perspektivisch - nicht emotional - distanzierte Blick schafft eine Komplexität der Darstellung des Krieges, bei der es zentral um die Frage der Schuld geht. Damit ist bereits angedeutet, dass es in dem Stück nicht um eine einseitige Schuldzuweisung geht, sondern um einen komplexen SchuldZusammenhang.

Zum Inhalt. Der Soldat Karl kann die Erinnerung an eine Massenerschießung, an der er auf Befehl seines Vorgesetzten Herbert teilnehmen musste, nicht verdrängen. Als er auch den Popen erschießen soll, desertiert er. $\mathrm{Zu}$ Hause wartet seine Frau Maria mit dem neugeborenen Kind darauf, dass Karl, der sein Kind noch nicht zu Gesicht bekommen hat, im Frühjahr heimkommen werde. 
Karls Vater, der Oberlehrer, ist ein Repräsentant des klassischen Bildungsbürgertums. Seitdem die Engländer die alte Stadt, an deren Geschichte und Kunst die ganze Bildungswelt des Oberlehrers hing, in Trümmern gelegt haben, fühlt er nur noch Hass auf die Feinde: „Satane sind es! Satane sind es!“ (Frisch 1976a: 92). Diese Worte bilden das Bindeglied des Perspektivenwechsels zu einer gegnerischen Bomberbesatzung, für die umgekehrt die Deutschen die Satane sind.

Deutlich wird hier nicht nur, dass der Krieg Hass statt Einsicht stiftet und dass daran alle Seiten beteiligt sind, deutlich wird auch eine gewisse Hilflosigkeit angesichts der Handlungsmöglichkeiten in einer solchen Unheilsituation: „Was sollen wir tun? [...] Sollen wir uns töten lassen?“ (Frisch 1976a: 98).

Als Karl sich nach Hause durchgeschlagen hat und seinem Vater die Gewissensgründe seiner Desertion darlegen will, kommt es zur entscheidenden Unterredung, bei der es zentral um Schuld und Verantwortung geht. Gegen die Vorwürfe des Sohnes rechtfertigt der Vater sich, indem er die Gründe seiner sukzessiven Verstrickung und Mitläuferschaft darlegt.

Diese Szene beschreibt in kurzen Worten eine ganz normale Mitläuferschaft als Chronologie des Ja-Sagens: erst die Sorge um die eigene Stelle, dann die Sorge um die Zukunft der eigenen Kinder, dann die Frage, ob man emigrieren soll, und schließlich bleibt, unter den Bedingungen einer totalitären Diktatur, nur noch das Ja-Sagen zu allem. Irgendwann war es zu spät, ,nein' zu sagen.

Bei aller Verständlichkeit der Motive des Vaters, bei aller Ethik des Gehorsams, den der Sohn geschworen hat, sie entlasten nicht von der unabtretbaren Verantwortung jedes Einzelnen und damit von der Schuld, auch wenn der Vater seinen Sohn dies glauben machen wollte. Schuld und Ausweglosigkeit - das ist die Situation, angesichts derer Karl beschließt, sich das Leben zu nehmen. In derselben Szene stürzt sich seine Frau, Maria, mit dem Kind in die Feuerhölle des Luftangriffs, in der sie umkommen.

Bilanz: der Oberlehrer hat nicht nur sämtliche Ideale verloren, auch seine Frau, seinen Sohn und sein Enkelkind. Seine Kompromissbereitschaft war „umsonst". Der Sohn Karl ist sein radikaler Gegenpol geworden: keine familiäre Bindung an Vater, Frau und Kind kann ihn davon abhalten, weitere Kompromisse mit dem Leben zu machen. Sein Gewissen, der Gesang der Toten, deren Stimmen immer wieder kommen - nun singen sie wieder! - stellt ihn in eine Situation der Ausweglosigkeit.

Schuld ist hier keine Kriegsschuldfrage (wer hat den Krieg begonnen?), sondern eine Frage des konkreten Verhaltens Aller: vor dem Krieg (der Lehrer und seine Kompromisse), im Krieg (Karl, die Bomberbesatzung, u.a.) und nach dem Krieg (die Überlebenden, die die Toten für ihre Rache instrumentalisieren). Die Schuld ist allgegenwärtig, aber dieser Umstand taugt mitnichten zur Entschuldigung des Einzelnen. 
Das Stück ist nicht nur in Deutschland, sondern auch in der Schweiz auf Kritik gestoßen. Interessant ist dabei vor allem, was Max Frisch auf einen Schweizer Leitartikel in der Neuen Zürcher Zeitung vom 23. Mai 1945 antwortete. Zunächst geht Max Frisch von der Frage aus, „ob wir unter den gleichen Bedingungen nicht ebenso schuldig hätten werden können“ (Frisch 1976b: 294). Sodann führt er den Vorwurf der heuchlerischen Selbstgerechtigkeit deutlich aus:

Auch dort, wo das Versagen des Geistes nicht zur aktiven Kriminalität reicht und sich nicht als Massaker darstellt, erkennen wir es als Schuld, beispielsweise in dem Umstand, dass unsere gesamte schweizerische Presse, solange es unser Vaterland hätte gefährden können, zu eben jenen Massakern schweigen musste und schwieg. Nur dass wir es beim Nachbar als Mangel an bürgerlichem Mut bezeichnen, somit als Schuld, im eigenen Lande aber als Staatsraison. Das meiste, was heute die öffentliche Empörung weckt, hätte auch unser Volk schon lange wissen können und müssen [...]. (Frisch 1976b: 295)

Max Frisch deckt damit die nach 1945 rasch sich international stabilisierenden Mechanismen im Umgang mit der Schuldfrage auf: die Instrumentalisierung der Anklage zum Zwecke der Ablenkung von der Frage nach der eigenen Mitverantwortung. Zunächst muss die Selbsterforschung stehen. Sodann ist aber auch klar: die Erkenntnis der Mitverantwortung Anderer erleichtert den Deutschen nicht im Mindesten die Last ihrer Schuld.

\subsection{Albrecht Goes Unruhige Nacht}

Die Frage der Allgegenwärtigkeit der Schuld und vor allem der Unentrinnbarkeit der Schuld wird auch in der Erzählung Unruhige Nacht (1949) von Albrecht Goes ausdrücklich thematisiert.

Albrecht Goes war 1942 bis 1945 als Lazarett- und Gefängnis-Geistlicher in Russland, Polen, Ungarn und Österreich im Einsatz. 1949 erschien Unruhige Nacht.

Das Buch thematisiert den christlichen Konflikt mit einem antihumanistischen Regime bzw. einer sich in der Armee spiegelnden in weiten Teilen areligiösen und verrohten Gesellschaft. Dabei geht es um die Frage der Verstrickung des Einzelnen und seines kleinen oder großen Beitrags zum Funktionieren der Mordmaschinerie. Schließlich geht es auch um die Opfer. Der Soldat Baranowski, ohne jede Liebe aufgewachsen, wollte sich ein Mal im Leben geliebt fühlen. Seine Schuld besteht darin, dass er von der Liebe zu einer ukrainischen Frau und zu ihrem Sohn ergriffen wurde und eine Zeitlang den Vater vertrat, der von den Deutschen erschossen worden war. Daraufhin wird er wegen Desertion zum Tode verurteilt. Die Nacht vor dieser Hinrichtung, in der der Kriegspfarrer die Akten des Verurteilten studiert, ist im Wesentlichen die erzählte Zeit der Novelle.

Der entscheidende Konflikt besteht für den Kriegspfarrer darin, dass er vom Militär zu einem Rädchen in der Mordmaschinerie degradiert wird: 
"Sorgen Sie dafür, daß die Sache glatt vonstatten geht" lauteten die Worte des Generals (Goes 1988: 16). Der Ich-Erzähler empfindet Ekel, sieht noch einmal den Nazimajor Kartuschke an und denkt: „Er war ohne Würde, dieser Offizier, so viel stand fest. (...) Aber was geschieht mit den Kartuschkes in diesem Heer? Und was geschieht nicht? Durch uns - nicht?" (Goes 1988: 16).

Das eigene Versagen, der ausbleibende eigene Widerstand, die eigene Verantwortung wird hier angesprochen. Dieser Widerstand unterbleibt, um „dem Verurteilten eine letzte, ruhige Erdennacht zu lassen“ (Goes 1988: 21). Das moralische Problem ergibt sich nun daraus, dass Ruhe - wenngleich nicht im Sinne von Seelenfrieden, sondern von Ruhe und Ordnung - zugleich ganz im Sinne der Militärkommandantur ist und es somit zu einer Koinzidenz von geistlichem und militärischem Anliegen kommt, die de facto die Arbeit des Geistlichen in den Dienst eines reibungslosen Funktionierens des militärischen Strafvollzugs stellt.

Angesichts dieses Dilemmas legt der Ich-Erzähler ein Schuldeingeständnis ab, das aber von konkreter Schuld nichts weiß, sondern - in alttestamentarischer Tradition - den Einzelnen qua Existenz unauflöslich in die Bösartigkeit dieser Welt verstrickt sieht. Im Gespräch mit einem anderen Kriegspfarrer sagt er:

\footnotetext{
Sie haben mich vorhin gefragt, worin wir uns denn von Kartuschke und den Seinen unterscheiden und was wir tun sollen. Vielleicht unterscheiden wir uns wirklich nur dadurch, daß wir nie, zu keiner Stunde gutheißen, was nicht gut ist. Wahr, bitter wahr: wir sind hineinverstrickt, der Hexensabbat findet uns schuldig, uns alle. Auch Baranowski ist ja nicht ohne Schuld, und kein englischer Chaplain kommt daran vorbei, einen Fahnenflüchtigen auf solchem Gang zu begleiten. Unsere Schuld aber ist, daß wir leben. Nun müssen wir leben mit dieser Schuld. (Goes 1988: 32).
}

Überleben als Schuld? Diesen Gedanken finden wir so ähnlich auch bei Karl Jaspers - weiter unten. Nachdem der Pfarrer seine geistliche Aufgabe gelöst hat, kommt prompt die Anerkennung, die alles in Frage stellt: „Tadellos hingekriegt haben Sie das", sagte der Kriegsgerichtsrat (Goes 1988: 59). Und beim Abschied erneut: „Nochmals meine Anerkennung. Sie verstehen Ihr Metier." (Goes 1988: 60).

Das „Metier“ bedeutet für ihn: Ruhigstellung, emotionale Narkotisierung, damit alles „reibungslos“ abläuft. Der Ich-Erzähler kann nicht verhindern, dass man seine seelsorgerische Aufgabe dergestalt instrumentalisiert und ihn somit in die Torheit der Welt involviert. Seine Haltung: „Ich ließ es gelten, daß es so war." (Goes 1988: 58). Hauptsache, er war Baranowski nahe gewesen.

Die abschließenden Gedanken des Buches sind selbstkritisch der Frage der eigenen (Mit-)Schuld gewidmet: „Wer auf diesem Planeten hinwandert, wird schuldig werden, es ist ein unergründliches Gesetz. Es ist ein eiserner Ring, und ihr sollt es wissen." (Goes 1988: 66) Das ist eine Entgrenzung der Schuld zu einer Allgemeinschuld qua conditio humana, die auch die Kriegsparteien der 
anderen Länder mit einschließt. Diese Allgemeinschuld, die missverstanden zu dem Gedanken verführen könnte, wo alle schuldig sind, ist keiner mehr schuldig, erhält ihr produktives Potenzial aber aus der Allgemeinverantwortung, die ihr zugrunde liegt und die letztlich auch zu der Frage führt: Welche Mitschuld haben wir, dass ein Kartuschke von seiner ursprünglichen Priesterlaufbahn abgekommen ist und nur noch bei Hitler Hoffnungen auf eine Karriere finden konnte? Welche Verantwortung haben wir für die vom Wege Abgekommenen?

Diese wenigen Einblicke in die Nachkriegsliteratur zeigen, dass das Thema der Schuld existenziell, sehr konkret und ausgesprochen komplex thematisiert wurde. In allen Texten geht es um die Erfahrung einer Allgegenwärtigkeit der Schuld, um einen umfassenden Schuldzusammenhang und in bestimmten Situationen sogar um eine Unentrinnbarkeit der Schuld.

Fast zeitgleich entstehen die essayistischen Abhandlungen von Hannah Arendt Organisierte Schuld und Karl Jaspers Aufsatz Die Schuldfrage, die in ihrer gedanklichen Durchdringung der Komplexität der Schuldfrage bis heute unübertroffen sind.

\section{Die PHILOSOPHISCHE BeHANDLUNG DeR SCHULDFRAGE UNMITTELbaR NACH KRIEGSENDE: HANNAH ARENDT UND KARL JASPERS}

Im April 1946 druckte die Monatsschrift Die Wandlung die deutsche Originalfassung eines im November 1944 verfassten und im Januar 1945 in der Zeitschrift Jewish Frontiers auf Englisch erschienen Artikels von Hannah Arendt mit dem Titel: Organisierte Schuld. Darin stellt Hannah Arendt drei Thesen auf, die im Kern darauf hinauslaufen, dass der Völkermord an den Juden nicht nur eine deutsch-jüdische Angelegenheit sei.

Sie deutet erstens die Verbrechen der Nationalsozialisten als Problem des Totalitarismus, und damit als ein Produkt der Massengesellschaften des 20. Jahrhunderts. In ihnen komme es zu einem typischen Phänomen der Moderne: dem Bündnis von Machthabern und Pöbel. Zweitens verwische der Staatsapparat totalitärer Gesellschaften die moralische Verantwortung des Einzelnen durch das Prinzip der delegierten und verteilten Verantwortung: genau darum konnte ein Eichmann behaupten, er habe persönlich gar nichts gegen Juden und er habe nur seine Pflichten im Rahmen organisatorischer Gesamtaufgaben erfüllt, als kleines Rädchen in einer großen Maschinerie.

Der „Kern der Sache“ besteht für Arendt folglich darin, dass die Deutschen sowohl Opfer und Geisel der NS-Machthaber geworden sind, als auch durch den Erfolg der totalen Mobilmachung zu deren Komplizen und somit mitschuldig geworden sind. Opfer und Täter zugleich. Zum „Kern der Sache" gehört für Arendt weiterhin die Einsicht, dass diese Verbrechen zwar historisch, aber nicht genetisch oder "rassisch“ ein "Monopol“ (Arendt 1946: 344) der Deutschen darstellen, sondern unter den Bedingungen der Moderne 
prinzipiell bei allen Menschen möglich sind: „Seit vielen Jahren begegnen mir Deutsche, welche erklären, daß sie sich schämten, Deutsche zu sein. Ich habe mich immer versucht gefühlt, ihnen zu antworten, daß ich mich schämte, ein Mensch zu sein“(Arendt 1946: 343).

Damit gab Hannah Arendt bereits 1944, als sie diesen Artikel verfasste, das eigentliche Ziel aller Aufklärung über den Holocaust, ja über Gewalt und Genozide schlechthin vor: zu verstehen, dass das Ermorden Unschuldiger keineswegs nur großen Bösewichten und Psychopathen vorbehalten ist, wie sie noch die Romane des 19. Jahrhunderts bevölkerten, sondern dass das Böse in den arbeitsteiligen Gesellschaften des 20. Jahrhunderts einen ganz selbstverständlichen Charakter ${ }^{9}$ angenommen hat, ausgeübt von durchschnittlichen Angehörigen einer totalitären Massengesellschaft, von „ganz normalen Männern“.10 60 Jahre später konnte daher Susan Sontag denjenigen, die sich noch immer davon „überraschen lassen“, „welche Grausamkeiten Menschen einander antun können“, bescheinigen, sie seien „moralisch oder psychologisch noch nicht erwachsen geworden. “11 Daran, dass es bei dieser Form von moralischer und psychologischer Mündigkeit weder um Selbstgerechtigkeit geht, noch um Deutschenhass, sondern um anthropologische Wahrheiten, ließ Arendt bereits damals keinen Zweifel:

\begin{abstract}
Vielleicht haben jene Juden, deren Väter die erste Konzeption der Idee der Menschheit zu danken ist, etwas über diese Last gewußt, wenn sie alljährlich (...) nicht nur alle in der Gemeinde begangenen Sünden, sondern alle menschlichen Verfehlungen überhaupt auf sich nahmen. Diejenigen, die heute bereit sind, in moderner Form diesen Weg wieder zu gehen, haben sich vermutlich nicht pharisäisch mit dem Stoßß-Seufzer des ,Gott-seiDank-bin-ich-nicht-so' über die ungeahnten Möglichkeiten des 'deutschen Nationalcharakters' entsetzt; dafür haben sie in Furcht und Zittern endlich begriffen, wessen alles der Mensch fähig ist - und dies ist in der Tat eine Vorbedingung modernen politischen Denkens. (Arendt 1946: 344).
\end{abstract}

An diesem Punkt trifft sie sich mit dem, was Karl Jaspers in seinem im Juni 1946 erschienen Aufsatz Die Schuldfrage als „metaphysische Schuld" bezeichnete. Jaspers unterschied vier Schuldbegriffe:

1. Kriminelle Schuld: sie bezieht sich auf Handlungen, die gegen bestehende Gesetze verstoßen.

2. Politische Schuld: sie besteht in der Mitverantwortung eines jeden Bürgers dafür, von wem und wie er regiert wird.

3. Moralische Schuld: sie bezieht sich auf die Handlungen des Einzelnen, der für alle seine Handlungen die moralische Verantwortung trägt:

9 Vgl. Hannah Arendt (1965): Eichmann in Jerusalem. Ein Bericht von der Banalität des Bösen. Der Originalbericht erschien 1963 auf Englisch, wo das Wort ,banality soviel bedeutet wie Allgemeingültigkeit, Selbstverständlichkeit. Die deutsche Übersetzung durch ,Banalität' ist daher irreführend.

10 Vgl. Browning 1996.

11 Sontag 2003: 135. 
"Niemals gilt schlechthin >Befehl ist Befehl<."(Jaspers 1946: 10)

4. Metaphysische Schuld - hier kehrt der Menschheitsgedanke Hannah Arendts wieder:

Es gibt eine Solidarität zwischen Menschen als Menschen, welche einen jeden mitverantwortlich macht für alles Unrecht und alle Ungerechtigkeit in der Welt, insbesondere für Verbrechen, die in seiner Gegenwart oder mit seinem Wissen geschehen. Wenn ich nicht tue, was ich kann, um sie zu verhindern, so bin ich mitschuldig. (Jaspers 1946: 11).

Jaspers bietet hier eine Argumentation, die darauf hinausläuft, dass es unter Umständen unmöglich ist, nicht schuldig zu werden, insofern nämlich die moralische Forderung, sein Leben nicht sinnlos zu opfern, sondern für die Verwirklichung des Sinnhaften in der Welt zu bewahren, in Konflikt treten kann mit der metaphysischen Forderung absoluter Mitmenschlichkeit:

Diese Solidarität ist verletzt, wenn ich dabei bin, wo Unrecht und Verbrechen geschehen. Es genügt nicht, daß ich mein Leben mit Vorsicht wage, um es zu verhindern. Wenn es geschieht, und wenn ich dabei war, und wenn ich überlebe, wo der andere getötet wird, so ist in mir eine Stimme, durch die ich weiß: daß ich noch lebe, ist meine Schuld. (Jaspers 1946: 48f).

\section{SCHLUSS}

Diese unmittelbar nach Kriegsende publizierten, teilweise noch im Krieg verfassten literarischen und philosophischen Versuche der Verarbeitung des Grauens verweisen auf unterschiedliche Grade der Verstrickung in das Böse, unterschiedlichste Möglichkeiten des Schuldig-Werdens, Varianten des Schuldlos-schuldig-Werdens, präsentieren Menschen die durch Überforderung schuldig werden und Situationen, in denen es unmöglich ist, nicht schuldig zu werden und kennen den Konflikt zwischen der Pflicht, sein Leben zu bewahren und dem Überleben als Schuld gegenüber den Toten. Sie präsentieren Schuldhaftigkeit als eine conditio humana, von der sich niemand völlig freisprechen kann und bestechen durch Einsichten in die Komplexität der Schuldfrage, die in den Debatten um die Amnestiegesetze Adenauers zwischen 1949 und 1954, im Anklagehabitus seit den 60er Jahren und in der Kommerzialisierung der Vergangenheit seit den 90er Jahren nur noch selten zu finden sind. Das Erkenntnis leitende Interesse der hier behandelten Philosophen und Literaten der Kriegsgeneration ist ein existenzielles, nämlich die Frage: Was ist meine, was ist unsere Schuld? Wie konnte das geschehen? Wer trägt dafür die Verantwortung?

Anklage ist hier immer zugleich auch Selbsthinterfragung. Dieser Aspekt geht schon ab den Fünfzigerjahren verloren. Und damit auch ein Stück Glaubwürdigkeit. 


\section{BIBLIOGRAFIE}

ARENDT, H. (1946), „Organisierte Schuld“, Die Wandlung, 4, 333-344.

ARENDT, H. (1965), Eichmann in Jerusalem. Ein Bericht von der Banalität des Bösen, München, Piper.

ASSMANN, A. (2006), Der lange Schatten der Vergangenheit. Erinnerungskultur und Geschichtspolitik, München, Beck.

BORCHERT, W. (2007), Das Gesamtwerk, Reinbek, Rowohlt.

BÖsCH, Fr. und GoschleR, C. (Hg.) (2009), Public History. Öffentliche Darstellungen des Nationalsozialismus jenseits der Geschichtswissenschaft, Frankfurt a. M. und New York, Campus.

BROSZAT, M. (1979), ,,,Holocaust' und die Geschichtswissenschaft“", Vierteljahreshefte für Zeitgeschichte, 2, 285-298.

BROWNING, Chr.R. (1996), Ganz normale Männer. Das Reserve-Polizeibatallion 101 und die $>$ Endlösung< in Polen, Reinbek, Rowohlt.

BURCKHARDT, J. (1950), Weltgeschichtliche Betrachtungen, Historisch-Kritische Gesamtausgabe, hg. und eingl. von Rudolf Stadelmann, Pfullingen, Neske Verlag.

FISCHER, T. und LORENZ, M.N. (Hg.) (2007), Lexikon der >Vergangenheits-bewältigung< in Deutschland. Debatten und Diskursgeschichte des Nationalsozialismus nach 1945, Bielefeld, Transcript Verlag.

FREI, N. (1996), Vergangenheitspolitik. Die Anfänge der Bundesrepublik und die NSVergangenheit, München, dtv.

FRIEDRICH, J. (2007), Die kalte Amnestie. NS-Täter in der Bundesrepublik, Berlin, List.

FRISCH, M. (1976), Gesammelte Werke in zeitlicher Folge, Band II.1 (1944-1949), hg. v. Hans Mayer, Frankfurt a.M., Suhrkamp.

FRISCH, M. (1976b), „Verdammen oder verzeihen? Ein Brief an Bi, den Verfasser des Leitartikels in der NZZ vom 23.5.1945" in ders., Gesammelte Werke in zeitlicher Reihenfolge, Bd. II.1. 1944 -1949, hg. v. Hans Mayer, Frankfurt a. M., Suhrkamp, 294-295.

GOES, A. (1988), Unruhige Nacht, Stuttgart, Reclam.

JASPERS, K. (1946), Die Schuldfrage. Ein Beitrag zur deutschen Frage, Zürich, Artemis.

JUDT, T. und SNYDER, T. (2015), Nachdenken über das 20. Jahrhundert, Frankfurt a. M., Fischer.

MÜLlER-GANGlOFF, E. (1949), „Faust als Fliegergeneral“, Berliner Hefte für geistiges Lebens, 4, 93. Zitiert in Des Teufels General. Grundlagen und Gedanken zum Verständnis des Dramas, Mews, S., Frankfurt a. M., Diesterweg, 1979, 45.

NOLTE, E. (1987), Der europäische Bürgerkrieg 1917-1945. Nationalsozialismus und Bolschewismus, München, Herbig.

REICHEL, P. (2001), Vergangenheitsbewältigung in Deutschland. Die Auseinandersetzung mit der NS-Diktatur von 1945 bis heute, München, Beck.

SCHLINK, B. (1997), Der Vorleser, Zürich, Diogenes.

SONTAG, S. (2003), Das Leiden anderer betrachten, München und Wien, Hanser.

StOlleis, M., FreI, N. und VAN LAAK, D. (Hg.) (2000), Geschichte vor Gericht. Historiker, Richter und die Suche nach Gerechtigkeit, München, Beck.

TÖTEBERG, M. (2007), „Nachwort“ in Das Gesamtwerk, Borchert, W., Reinbek, Rowohlt, 547-570. 
WeIGEL, S. (2002), "Zeugnis und Zeugenschaft, Klage und Anklage. Zur Differenz verschiedener Gedächtnisorte und -diskurse" in Gedächtnis, Geld und Gesetz. Vom Umgang mit der Vergangenheit des Zweiten Weltkrieges, Weigel, S. und Tanner, J. (Hg.), Zürich, vdf Hochschulverlag, 39-62.

WILDT, M. (2000), „Differierende Wahrheiten. Historiker, Richter und die Suche nach Gerechtigkeit" in Geschichte vor Gericht. Historiker, Richter und die Suche nach Gerechtigkeit, Stolleis, M., Frei, N. und van Laak, D. (Hg.) München, Beck, 46-59.

ZUCKMAYER, C. (1969), Als wär's ein Stück von mir, Frankfurt a. M., Fischer.

ZuCKMAYER, C. (1973), Des Teufels General, Frankfurt a. M., Fischer.

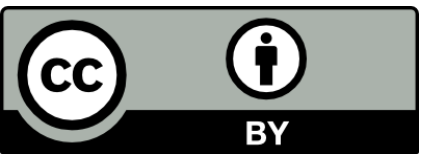

Llevat que s'hi indiqui el contrari, els continguts d'aquesta revista estan subjectes a la llicència de Creative Commons: Reconeixement 3.0 Espanya. 